\title{
Murine Leukemia Retrovirus Integration Induces the Formation of Transcription Factor Complexes on Palindromic Sequences in the Signal Transducer and Activator of Transcription Factor $5 a$ Gene During the Development of Pre-B Lymphomagenesis
}

Tatsuaki Tsuruyama, ${ }^{*}$ Takuya Hiratsuka, ${ }^{\dagger}$ Guang Jin, ${ }^{\ddagger}$ Yukiko Imai, ${ }^{*}$ Haruya Takeuchi, ${ }^{*}$ Yasuhiro Maruyama, ${ }^{\S}$ Kazuya Kanaya, ${ }^{\S}$ Munetaka Ozeki, ${ }^{*}$ Tetsuya Takakuwa, ${ }^{\neq \S}$ Hironori Haga," Keiji Tamaki, ${ }^{\text {" }}$ and Takuro Nakamura ${ }^{\ddagger}$

Murine leukemia retrovirus (MLV) vectors are highly effective tools for introducing a foreign gene into a target host genome. However, it remains unclear how integrated retroviral promoter activity is influenced by the upstream or downstream sequences and how the host cell phenotype is influenced by the integrated promoter activity. Herein, we analyzed a set of pre-B lymphoma clones in which the $M L V$ genome was integrated into the signal transducer and activator of transcription factor 5a (Stat5a) gene. Among the clones, the lymphoma clones with a provirus integrating into the middle position of the palindromic target sequences showed significantly higher transcription of the Stat 5 a gene; and $\mathbf{p 3 0 0}$ and other transcriptional factors formed complexes, with binding to the proviral-host junctional DNA segment. By using a luciferase assay, the upstream and downstream sequences of the provirus contributed to the up-regulation of proviral promoter activity. In concomitance with the higher Stat5a transcription, the immunoglobulin gene recombination was arrested. Antiapoptotic activity was significantly higher, with an increase in Bcl-xL, one of the targets of STAT5A, when IL-7 was supplied. Thus, a minute difference between MLV integration sites can lead to large differences

in the host phenotype through the formation of transcription factor complexes on the proviral-host junctional DNA segment, suggesting that caution is necessary in monitoring integration sites when working with MLV vectors. (Am J Pathol 2011, 178:1374-1386; DOI: 10.1016/j.ajpath.2010.12.012)

Retrovirus-based vectors have been used as an available tool for the introduction of a gene into the host genome in gene function analyses. Transgene transcription is predominantly controlled by the integrated retroviral promoter element in the long terminal repeat (LTR) in the vector sequence. However, because the retroviral promoter activity is affected by the integration site, the expression of a transgene is not necessarily adequate. The lack of control of retroviral integration limits its application in transgenic animal studies and gene therapy, which first and foremost must be safe for patients. Indeed, there is some risk that a murine leukemia retrovirus (MLV)-based vector could induce host malignant transformation by integration into an oncogene in the genome of a patient undergoing gene therapy. ${ }^{1}$ Therefore, considerable attention has been given to the choice of appropriate vector integration sites for the induction of induced pluripotent stem cells from mouse embryonic or adult fibroblasts. ${ }^{2}$ In fact, lack of control over

Supported by a Grant-in-Aid for Cancer Research from the Ministry of Education, Culture, Sports, Science and Technology of Japan and by the Ministry of Health, Labor and Welfare of Japan (grant 7013086 to T.N. and T.T.).

K.T. and T.N. contributed equally to this work.

Accepted for publication December 1, 2010.

None of the authors disclosed any relevant financial relationships.

Supplemental material for this article can be found at http://ajp. amjpathol.org or at doi:10.1016/j.ajpath.2010.12.012.

Address reprint requests to Tatsuaki Tsuruyama, M.D., Ph.D., Department of Forensic Medicine and Molecular Pathology, Graduate School of Medicine, Kyoto University, Yoshidakonoecho, Sakyo-ku, Kyoto 606-8501, Japan. E-mail: tsuruyam@fp.med-u.ac.jp or tsuruyam@kuhp.kyoto-u.ac.jp. 
the integration site has limited the application of MLV vectors; it remains unclear to what extent the integration site influences retroviral promoter activity and host phenotype changes.

Furthermore, proviral promoter activity was compared under the expression of diverse-and not commongenes, which makes it impossible to render a consistent comparison. Because of these limitations associated with previous studies, the factors contributing to making proviral promoter activity exceedingly sensitive to minute nucleotide differences in the integration sites remain largely unstudied. The present investigation used comparative analysis of the activity of the MLV promoter integrated into an identical intron of the signal transducer and activator of transcription factor $5 a$ (Stat5a) gene. We report that the activity is significantly influenced by the sequences flanking the retroviral integration sites and that the expression levels of the host gene can alter the host cell phenotype, as exemplified by hematopoietic cell differentiation and tumorigenesis induced by MLV integration.

In this article, we used a set of pro- to pre-B lymphoma clones containing the MLV genome integrated into variable sites within the second intron of the Stat5a gene, which is one of the common integration sites of MLV. ${ }^{3,4}$ The encoded protein is a member of the STAT family and forms a dimer that translocates into the nucleus and exerts transcriptional activity by binding to the gamma interferon activation site element in the promoter of target antiapoptotic genes, such as c-myc, pim-1, bc/xL, and cyclin $\mathrm{D} 1,{ }^{5}$ that regulate proliferation and antiapoptosis in hematopoietic cells. ${ }^{6,7}$ This signaling molecule in the IL-7 receptor pathway is limitedly operative during the precursor stage in the pro- to pre-B-cell lineage. ${ }^{8}$ The STAT5A contributes to IL7-induced B-cell precursor expansion. ${ }^{9}$ Schwaller et al ${ }^{10}$ have reported that Stat5a is essential for the myeloproliferative and lymphoproliferative diseases induced by Janus kinases. We supported their evidence by identifying the pro- or early pre-B-cell lymphomas using MLV integration into Stat5a. ${ }^{4}$

In the clones with MLV integration into Stat5a, we analyzed the correlation of the expression levels of the gene and MLV integration because varied STAT5A expression levels were expected to influence the degree of precursor expansion, probably affect Ig heavy chain $(I g H)$ gene recombination in the host pre-B cells, and induce maturation arrest. To confirm the data on the MLV integration site and the expression levels of the target neighboring gene, we generated reporter gene assay vectors that consisted of the $M L V$ genome either lacking or containing defective transcription factor-binding motifs within the retroviral LTR and the upstream and downstream sequences that originated from the Stat5a sequence. The downstream sequences were inserted upstream of luciferase as the reporter gene. Analysis of luciferase activity allowed us to investigate how different integration sites in the flanking sequence affect $M L V$ promoter activity. Taken together, the data are consistent with the model presented herein for the control of retroviral promoter activity via interaction between the retroviral genome element and the host flanking sequence. The obtained data were used to construct a model demonstrating how a proviral genome in the target Stat5a sequence influences the proviral promoter activity and host cell phenotype.

\section{Materials and Methods}

\section{Mice and Lymphoma Clones}

All mice used in this study were handled in strict accordance with the guidelines for good animal practice, as defined by the relevant national and local animal welfare bodies; and all animal work was preapproved by the Kyoto University Ethics Committee for Animal Experiments. The SL/Kh mice were obtained from the RIKEN Bioresource Center, Tokyo, Japan. This strain possesses a pathogenetic endogenous ecotropic murine virus (Emv11) that was mapped on chromosome $7,{ }^{11}$ which is shared with the AKR/J mouse strain. ${ }^{12}$ In addition, more than five copies of the endogenous murine leukemia retroviral genome, in addition to Emv11, are observed (Figure 1B, left). The identified endogenous MLV genomes are shown in Supplemental Table S1 (at $h$ ttp://ajp.amjpathol.org).

In the SL/Kh strain, the pro- to pre-B cells in the bone marrow (BM) acquire more than one copy of the proviral genome; and more than $90 \%$ of these mice develop $\mathrm{BP}_{-1} 1^{+} \mathrm{slgM}^{-}$pro- or pre-B lymphomas spontaneously by the age of 6 months. ${ }^{4,11}$ Lymphoma cells of the swelling lymph node, $2.0 \times 10^{8}$, were obtained from a lymph node of a 6-week-old SL/Kh mouse and incubated in methylcellulose-based medium (Methocult) containing IL-7 for pro- to pre-B cells (Stemcell Technology, Vancouver, British Columbia, Canada) or in RPMI 1640 medium (Invitrogen, Carlsbad, CA) with 20-ng/ml IL-7, IL-3, IL-4, or stem cell factor (Peprotec, London, England). ${ }^{4}$

\section{Southern Hybridization to Detect MLV Insertional Recombination in Stat5a}

High-molecular-weight DNA samples were extracted from lymphoma and normal kidney tissues, and 2.5-mg aliquots of the DNA were digested with the Ncol restriction enzyme (New England Biolabs, Beverly, MA) for 16 hours and transferred to an $\mathrm{N}^{+}$nylon membrane (Hybond; GE Health Care, Buckinghamshire, England) after electrophoresis. The probe used was previously described. ${ }^{4}$

\section{Inverse PCR Method for the Detection of the $M L V$ Integration Site}

The inverse PCR method was previously described. ${ }^{4}$ The primers for inverse PCR were located within the MLV (Emvll) genomes. Their sequences were as follows: 5B4, 5'-GAGGGCTTGGACCTCTCGTCTCCTAAAAAACCACG-3'; and 5F1, 5'-GTCTCTCCCAAACTCTCCCCCTCTCCAACC-3' (first set). In addition, these sequences were used: $5 F 2$, 5'-CCTCCTCTGACGGAGATGGCGACAGAGAAGAGG-3'; and 5B1, 5'-GAGGGCTTGGACCTCTCGTCTCCTAAAAGAACCACG-3' (second step of the cycles for nested $P C R)$. The amplicons were then subcloned into a vector (pCR 2.1-TOPO; Invitrogen), and sequence analysis reactions were performed. 
B

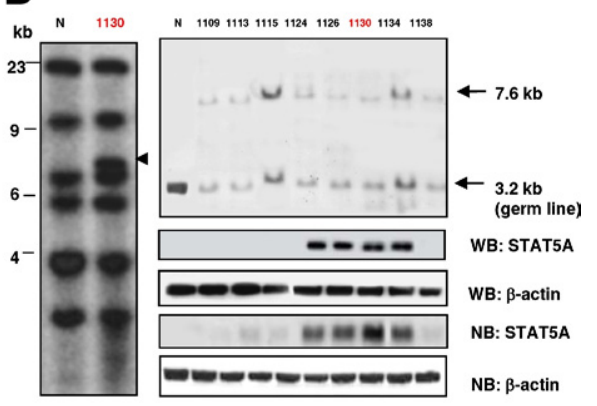

C

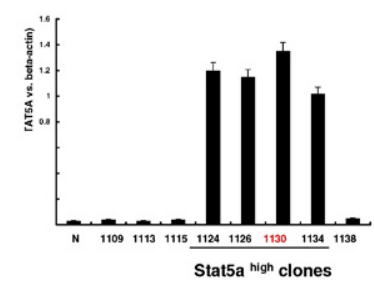

Figure 1. Genome integration of MLV provirus into Stat $5 a$. A: Clones with MLV integration into the second intron of Stat5a (GENEBANK, AF049104). The two open boxes and the closed box in the Stat 5 a structure represent the untranslational exons and the third translational exon, respectively. The numbers represent the nucleotide number from the start of the gene. The detailed sequence of the integration site is shown. The underlining represents the flanking sequence used in the $\mathbf{i}$ through vi vector constructs in Figure $2 \mathrm{~A}$. The red letter in the sequence represents the position of integration site 1130 within the intron. Palindromic sequence motifs are shown at the bottom. NcoI sites are shown. The upper inset shows blastic lymphoma tissue from SL/Kh mice (Giemsa staining, original magnification $\times 600$ ). Probe indicates the position of the probe used in the Southern hybridization assay. ${ }^{4}$ The MLV-Stat $5 a$ chimera mRNA is shown below. The represented $g u$ motif is the splicing signal sequence at the 1158 nucleotide. The bottom shows the result of the RT-PCR assay for chimera cDNA, including MLV RU5 (69 bp), the second intron ( 24 to $34 \mathrm{bp}$ ), and the third exon (158 bp) of Stat $5 \mathrm{a}$. Lane numbers represent the integration sites. Arrows represent the PCR primer positions. B: Southern blot of an NcoI-digested DNA fragment displaying the insertional recombination. Left: Six copies of an endogenous retroviral genome (N, $1130)$ and a newly acquired proviral genome (1130, arrowhead). Right: Stat 5 a-derived fragments are visualized. The upper arrow highlights the NcoI-digested fragment obtained after Emv11 integration. Lane numbers represent the integration site. N indicates control BM pre-B cells of SL/Kh mice 3 weeks after birth; WB:STAT5A, Western blot of the lymphoma extract with an antibody for STAT5A. Fragments of $7.6 \mathrm{~kb}$ represent the NcoI-digested fragment obtained after MLV clonal integration. ( $\beta$-Actin was the control blot.) NB:STAT5A is the Northern blot of lymphoma mRNA. ( $\beta$-Actin was the control blot.) C: Relative intensity of STAT5A versus $\beta$-actin (control). The horizontal axis represents the nucleotide number from the start of the first exon of the Stat5a gene.

\section{PCR for the Detection of Recombination in $\mathrm{lgH}$ and Ig Light Chain}

The monoclonality was confirmed by PCR analysis after IgH diverse segment $\left(D_{H}\right)-\operatorname{lgH} J$ segment $\left(J_{H}\right)$ recombination using primers designed to amplify four possible junctions between the D-Q52 and $J_{H}$ regions. The primers were as follows: 5'-CACAGAGAATTCTCCATAGTTGATAGCTCAG-3' (D $\mathrm{D}_{\mathrm{H}}$ 52-1 [sense]) and 5'-AGGCTCTGAGATCCCTAGACAG-3' (J $\mathrm{J}_{H} 4-1$ [antisense]). The PCR conditions were as follows: denaturation for 1 minute at $95^{\circ} \mathrm{C}$, annealing for 1 minute at $60^{\circ} \mathrm{C}$, and extension for 2.5 minutes at $72^{\circ} \mathrm{C}$ (28 cycles). After $D_{H}-Q 52-J_{H}$ recombination, the monoclonal lymphoma cells were selected from the other cells and used for the following assays. For the analysis of $\mathrm{V}$-J rearrangement, the degenerate $\mathrm{V}$ primer and another primer were used to amplify $V_{\kappa}$ to $\mathrm{J} 1-5 \kappa$ rearrangement, as previously described. ${ }^{13}$

\section{Flow Cytometry}

A suspension of single cells was prepared from lymphoma tissue. The cells were adjusted to $10^{6} \mathrm{cells} / \mathrm{ml}$; the total lymphoma cell yield was in the range of $0.8 \times 10^{7}$ to $1.2 \times 10^{7}$ cells. A single-cell suspension was prepared from both SL/Kh and BALB/C mouse femur BM plugs, and their densities were adjusted to $10^{6}$ cells $/ \mathrm{ml}$. The following antibodies were purchased commercially (BD Pharmingen, San Diego, CA): fluorescein isothiocyanate-labeled anti-
BP1 (clone 6C3) and phosphatidylethanolamine-labeled anti-B220 (clone RA3-6B2). The collected cells were incubated with normal rat serum for 15 minutes and stained with 1:10,000 diluted monoclonal antibodies for 15 minutes. After washing, the cells were analyzed using a scanner (FACScan; Becton Dickinson, Mountain View, CA). The $\mathrm{BP} 1^{+} \mathrm{B}_{22} \mathrm{O}^{+} \mathrm{BM}$ cells were purified from double-stained BM cells by cell sorting using a commercially available system (FACS Vantage; Becton Dickinson). The average yields from the BM cells of 4-week-old BALB/C and SL/Kh mice were $0.50 \%$ and $2.8 \%$, respectively. Genomic DNA was extracted from the purified cells using a kit (QIAamp DNA Blood Mini Kit; QIAGEN GmbH, Hilden, Germany). Apoptotic lymphoma cells, $0.8 \times 10^{7}$ to $1.2 \times 10^{7}$, were stained using $5 \mathrm{ml}$ of phosphatidylethanolamine-conjugated antibody (annexin $\mathrm{V}$ ) at room temperature in the dark for 15 minutes. A 400-ml binding buffer was added for flow cytometry analysis.

\section{Northern Blotting and RT-PCR Assay}

The methods were previously described ${ }^{4}$ The RT-PCR was performed using extracted RNA with a one-step RT kit (Invitrogen). The primers used were as follows: actin, 5'-CCTAAGGCCAACCGTGAAAAG-3' and 5'-TCTTCATGGTGCTAGGAGCCA-3'; terminal deoxytransferase, 5'-GAAGATGGGAACAACTCGAAGAG-3' and 5'-CAGGTGCTGGAACATTCTGGGAG-3'; Vpreb, 5'-CGTCTGTCCTGCTCATGCT-3' and 5'-ACGGCACAGTAATACACAGCC-3'; 
CD79a, 5'-ATCACATGGTGGTTCAGCC-3' and 5'-TCTCCAATGTGGAGGTTGC-3'; and CD19, 5'-TGTCTCTTCTGAGAAGCTGGC-3' and 5'-AACCAGAAGTGGACCTGTGG-3'. The RT-PCR primers for the Ig $\kappa$ light chain were as follows: 5'-GGCTGCAGSTCCAGTGGCAGTGGRTCWGGRAC-3' and 5'-CATTCCTGTTGAAGCTCTTGACAATGGGTG-3'. The RT-PCR primers for the $\lg \lambda$ light chain were as follows: forward, 5'-GCCTTTCTACACTGCAGTGGGTATGCAACAAT-3'; and reverse, 5'AGCCACTYACCTAGGACAGTSASYTTGGTTCC-3'. For real-time PCR assays for the detection of proviral RNA in the lymphomas, total RNA was reverse transcribed using a kit (Omniscript RT kit; Qiagen). For relative quantification by RT-PCR, 20 ng of each cDNA was analyzed using a kit (FastStart DNA Master SYBR Green I; Roche Diagnostics, Mannheim, Germany) with software version 3.5. For each primer pair, a standard curve was developed. To detect Emv11-Stat5a chimera RNA, the following primer set was used: MLV U5-Stat5a exon3-1F, 5'GAATCGTGGTCTCGCTGATC-3'; and MLV U5-Stat5a exon 3-1R, 5'-CCTGGAGCTGTGTGGCATAG-3'.

\section{Antibodies for Western Blotting of STAT5A}

Cell lysate was precleared using protein G-Sepharose (Sigma-Aldrich, St Louis, MO) at $4^{\circ} \mathrm{C}$ with 1 hour of agitation. The cleared lysate, $400 \mu \mathrm{L}$, was incubated with minimal essential medium $59,50 \mu \mathrm{L}$, at $4^{\circ} \mathrm{C}$ overnight; then, protein G-Sepharose, $50 \mu \mathrm{L}$, was added and incubated for an additional hour. After centrifugation, immunocomplexes were washed three times with a radioimmunoprecipitation assay buffer $(25 \mathrm{mmol} / \mathrm{L}$ Tris- $\mathrm{HCl}, \mathrm{pH}$ 8.0; $150 \mathrm{mmol} / \mathrm{L} \mathrm{NaCl}$; and $1 \% \mathrm{NP} 40$, a protease inhibitor mixture [Complete Mini EDTA-free; Roche Diagnostics]), resuspended in the sample buffer, and boiled for 5 minutes. The released proteins were examined by Western blotting. Antityrosine phosphorylated STAT5A was purchased from New England BioLabs (Ipswich, MA) and Santa Cruz Biotechnology (Santa Cruz, CA) (sc-11761). Purified anti-STAT5A and anti-STAT5B were obtained from ZYMED (San Francisco, CA). Antibodies toward $\beta$-actin (C4), p300 (sc-81349), GATA1 (sc-266), GATA2 (sc-267), Runx1 (sc-28679), Bcl-xL (sc-7122), CREB (sc20), and CRE-BP1 (sc-8398) were also purchased from Santa Cruz Biotechnology (sc-47778). Streptavidin-peroxidase conjugate was acquired from DAKO (Gostrup, Denmark). The blot was measured using a chemiluminator (Aishin, Nagoya, Japan).

\section{Vector Construction and Dual Luciferase Assay}

For a reporter gene assay, Ba/F3 cells were obtained from RIKEN cell bank (Tsukuba, Japan). After a 12-hour recovery period in the $10-\mathrm{ng} / \mathrm{ml}$ IL-3-containing medium, the cells were incubated in an RPMI 1640 medium supplemented with $0.5 \%$ bovine serum albumin for 12 hours or stimulated with the cytokine for the last 6 hours. The $\mathrm{Ba} / \mathrm{F} 3$ cells, $6.0 \times 10^{7}$, were transiently transfected by electroporation with $5 \mu \mathrm{g}$ of a luciferase reporter plasmid. Electroporation was performed according to a previously reported protocol. ${ }^{14}$ In each experiment, samples were analyzed in triplicate; and each experiment was repeated five times. On the other hand, Iymphoma cells with the provirus integrating into Stat5a were maintained in an RPMI 1640 medium supplemented with 20\% fetal calf serum, mercaptoethanol, and $50-\mathrm{mg} / \mathrm{ml}$ penicillin-streptomycin. Reporter gene analysis was performed 48 hours after transfection (Tecan, Durham, NC).

Cell lysate was then subjected to an assay (DualLuciferase Reporter Assay System; Promega, Madison, WI); a pGL3-basic vector lacking SV40 promoter (Promega) was used as the backbone for Emv11-derived provirus-firefly luciferase vectors (o, i, ii, iii, iv, v, $\mathrm{vi}$, and vii) in the current study. The Hindlll site $(+53)$ in the multicloning site of the pGL3-basic vector was used to construct the firefly luciferase vector, including the Emv11 proviral genome that was inserted into the identical orientation of the firefly luciferase and the flanking Stat5a sequence shown in the o through vii constructs for the assay. The flanking Stat5a sequence originated from the second intron. As a control for luciferase measurements in transfections, pRL-TK (HSV-tymidine tyrosine kinase) renilla luciferase (Promega) was cotransfected with a firefly luciferase vector. Firefly luciferase activity was normalized to renilla luciferase activity.

\section{Preparation of MLV Integrase and Anti-Integrase}

Full-length murine retroviral integrase cDNA (GENEBANK, J01998) was obtained from an SL/Kh mouse and subcloned into multiple cloning sites (EcoRl and Xhol) of the transfer vector (pSYNGCH; Katakura Industries, Saitama, Japan). The procedures for the construction of the recombinant virus and viral infection of silkworm Bombyx mori larvae have been reported..$^{15}$ To construct the recombinant baculovirus, Abv baculovirus DNA, a linearized AcNPV-BmNPV hybrid-type baculovirus DNA (Katakura, Maebashi, Japan), $0.5 \mathrm{mg}$, and psYNGCH-Th integrase, $1 \mathrm{mg}$, were used to cotransfect a monolayer of $\mathrm{BmN}$ cells, $2 \times 10^{6}$ cells $/ \mathrm{ml}$, in the presence of liposomes (Insectin; Invitrogen). These cotransfected BmN cells were maintained at $27^{\circ} \mathrm{C}$ in a culture for 5 days. Silkworm pupae were infected with the supernatants and harvested after 6 days. The pupae were homogenated by suspension in $30 \mathrm{ml}$ of ice-cold homogenizing buffer $A$ $(20 \mathrm{mmol} / \mathrm{L}$ Tris- $\mathrm{HCl}, 150 \mathrm{mmol} / \mathrm{L} \mathrm{NaCl}, 1 \mathrm{mmol} / \mathrm{L}$ EDTA, $1 \mathrm{mmol} / \mathrm{L}$ EGTA, $1 \mathrm{mmol} / \mathrm{L}$ dithiothreitol [DTT], and $0.05 \%$ phenylthiourea, $\mathrm{pH}$ 8.0) containing a protease inhibitor mixture ( $1 \mathrm{mmol} / \mathrm{L}$ phenylmethanesulfonyl fluoride and 10 $\mathrm{mmol} / \mathrm{L}$ benzamidine) and disrupted at $3000 \mathrm{rpm}$ for 5 minutes. The homogenate was centrifuged at 38,000 rpm for 1 hour at $4^{\circ} \mathrm{C}$. After removal of the supernatant, the pellet was suspended in $30 \mathrm{ml}$ of homogenizing buffer $B$ (20 mmol/L Tris- $\mathrm{HCl}, 150 \mathrm{mmol} / \mathrm{L} \mathrm{NaCl}, 1 \mathrm{mmol} / \mathrm{L}$ EDTA, $1 \mathrm{mmol} / \mathrm{L}$ EGTA, $1 \mathrm{mmol} / \mathrm{L}$ DTT, and $0.05 \%$ phenylthiourea, $\mathrm{pH}$ 8.0) containing the protease inhibitor mixture and thoroughly mixed in a homogenizer (Dounce Teflon) on ice at $1000 \mathrm{rpm}$ for 10 strokes. The EDTA and DTT were added to the pellet at a final concentration of 10 $\mathrm{mmol} / \mathrm{L}$, followed by solubilization with a sulfobetaine detergent (Zwittergent 3-12; Calbiochem, San Diego). The 
final concentration of the detergent was $2 \% \mathrm{w} / \mathrm{v}$. The sample was stirred gently for 1 hour at $4^{\circ} \mathrm{C}$ and then centrifuged (Hitachi RP50-2 rotor) at 38,000 rpm for 1 hour at $4^{\circ} \mathrm{C}$. The supernatant was collected, and the integrase was purified by column chromatography using the His-tag expressed on the integrase. Because integrase tended to aggregate, we immediately used it in assays after the purification. The obtained integrase was immediately injected into rabbits for immunization for the production of polyclonal anti-integrase. The molecular weight of the recombinant integrase was confirmed by Western blot analysis using the prepared antibody.

\section{RNAi of Stat5a and Stat5b}

The Stat5a RNAi (sc-37009; Santa Cruz Biotechnology) and the homologue Stat5b RNAi or control small-interfering RNA (siRNA) (sc-37007) were used according to the manufacturer's protocol (Santa Cruz Biotechnology). In a six-well tissue culture plate, $8.0 \times 10^{5}$ cells were seeded per well in a 2-ml antibiotic-free normal growth medium supplemented with fetal bovine serum. The lymphoma cells were incubated for 18 to 24 hours at $37^{\circ} \mathrm{C}$ in a $\mathrm{CO}_{2}$ incubator. The siRNA duplex solution (solution A) was added directly to the diluted transfection reagent (solution B) using a pipette. The lymphoma cells were washed once with $2 \mathrm{ml}$ of an siRNA transfection medium (sc36868), and the medium was aspirated. We proceeded immediately to the next step. For each transfection, $0.8 \mathrm{ml}$ of an siRNA transfection medium was added to each tube containing the siRNA transfection reagent mixture (solution A plus solution B). After gentle mixing, the mixture was overlaid onto the washed lymphoma cells, and the cells were incubated for 5 to 7 hours at $37^{\circ} \mathrm{C}$ in a $\mathrm{CO}_{2}$ incubator. One milliliter of the normal growth medium containing twice the normal serum and antibiotic concentration ( $\times 2$ normal growth medium) was added without removing the transfection mixture. Because of low viability, we removed the transfection mixture and replaced it with a $\times 1$ normal growth medium. Next, the cells were incubated for an additional 96 hours. The medium was aspirated and replaced with fresh normal growth medium, and the protein was extracted and assayed by Western blotting using anti-STAT5A (ZYMED).

\section{Preparation of Nuclear Extracts and Electromobility Shift Assay}

The methods were previously described. ${ }^{4}$ The probes were double-stranded oligonucleotides corresponding to the Stat-binding motif on the bclxL gene promoter (5'GACTTTCCGAGGAAGGCATTTCGGAGAAGAC-3'). For a competition study, the extracts were incubated with 150 $\mathrm{mol} / \mathrm{L}$ excess of the unlabeled probe.

\section{Chromatin Immunoprecipitation Assay}

The chromatin immunoprecipitation (ChIP) assay was performed as previously described. ${ }^{14,16}$ The SL/Kh pre-B lymphoma clones were fixed with $1.0 \%$ formalde- hyde at $4^{\circ} \mathrm{C}$ for 1 hour. Soluble chromatin was immunoprecipitated with $4 \mathrm{mg}$ of primary antibodies overnight. The immune complex was eluted by incubation with a buffer containing $10 \mathrm{mmol} / \mathrm{L}$ DTT at $37^{\circ} \mathrm{C}$ for 30 minutes, diluted 50-fold, and reimmunoprecipitated with the second antibody. The same sets of fivefold serial dilutions of input DNA for determining the appropriate DNA concentration in the absence of nonspecific amplification and $2.5 \%$ to $5 \%$ purified ChIP DNA were subjected to PCR for 28 to 30 cycles. Control primers were used for determining the appropriate dilution. ${ }^{14}$ After confirming that the nonspecific amplification was not observed by dilution, the immunoprecipitated DNA was amplified using the following primers: exon3 of Stat5a, 5'-CACGGCTGGCTCTCGATCCAC-3'; and, for the repeat region in 3'-LTR of Emv11, 5'-CAATAAAGCCTTTTGCTGTTGC-3'. To amplify the provirus 5'-LTR-Stat5a junctional DNA, the following primers were used: exon2 of Stat5a, 5'-CAAGAGCCGTCAGGAGCCGTC-3'; and, for the repeat region in 5'-LTR of Emv11, 5'-CAGATATCCTGTTTGGCCCTAG-3'. To amplify the provirus 5 ' - LTR (U3RU5), the following primers were used: 5'-TGAAAGACCCCTTCATAAGGCTTA (U3)-3' and 5'GGCTCCGTGGAAGAACTGAC-3'. To amplify the provirus 3'-LTR (U3RU5), the following primers were used: 5'-AGACAGGATTTCGGTAGTGCAGG (P15E)-3' and 5'-ACAGCAAAGGCTTTATTGG-3'.

\section{Statistical Analysis}

Results are expressed as mean \pm SD unless otherwise stated. All statistical analyses were performed using computer software (StatView; Abacus Concepts, Berkeley, CA). An unpaired $t$-test was used.

\section{Results}

\section{Integration Sites in the Stat5a Gene}

In the current study, we analyzed a set of lymphoma clones with the Emv11-derived provirus integrated into the second intron of Stat5a (Figure 1A). ${ }^{4}$ Integration sites were frequently found within a 46-bp palindromic sequence, including the most frequent site (ie, 1130). Southern hybridization using the MLV env probe or the Stat5a DNA probe demonstrated a newly acquired $M L V$ genome integrating into Stat5a (Figure 1B, left and upper right).

There were significant differences in the expression level of STAT5A between the clones, whereas there were only minute differences in the integration sites; proviral genomes were identical. In particular, the expression of STAT5A was significantly higher in the lymphoma cells, with integration into sites between 1124 and 1134; in contrast, expression was not obvious in lymphoma cells with integration into other sites (Figure 1B, upper right, and Figure 1C). Thus, a minute difference between MLV integration sites led to large differences in the expression level of the target Stat5a. For the following analysis, we divided the clones into two groups on the basis of the expression level of STAT5A. Because constitutively and highly expressed STAT5A was observed in the clones with MLV integration into the 1124 to 
A

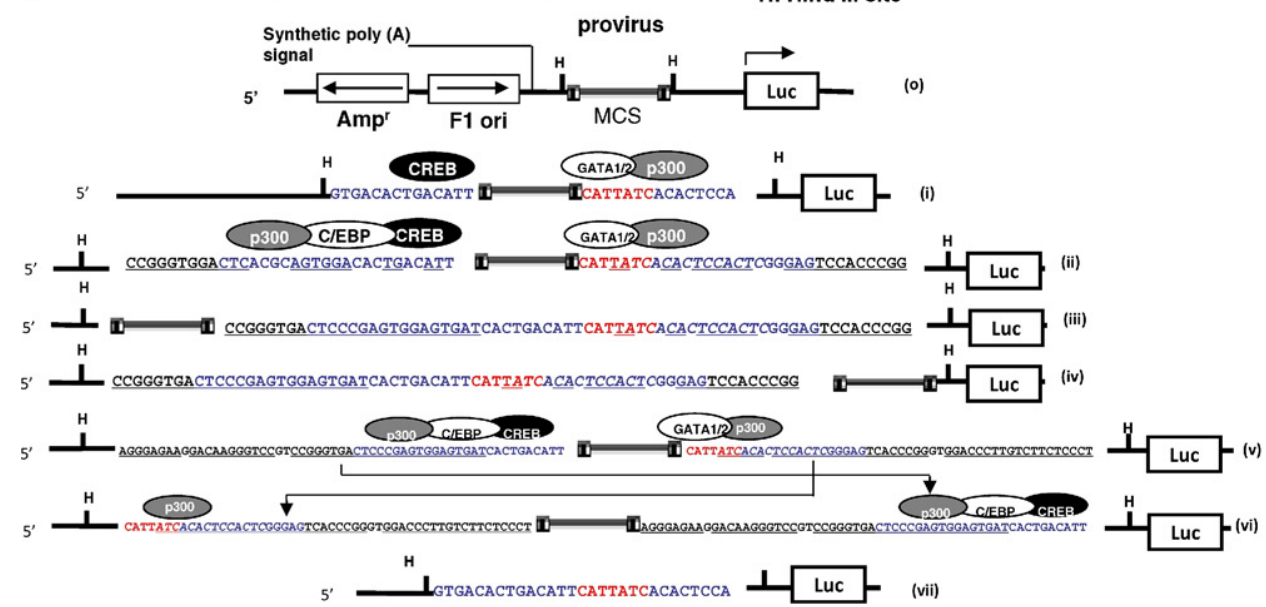

B

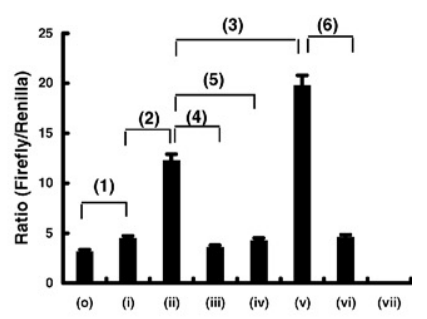

Figure 2. Luciferase assay using the Stat5a-derived sequence and $M L V$ provirus genome. A: Sequences of the luciferase assay vectors. $\mathbf{o}$, The pGL3-Emv11 vector did not have the MLV flanking sequence. The pGL3 structure is shown. Luc represents Firefly luciferase in the pGL3 basic vector. The sequences of $\mathbf{i}$ through vi pGL3 vectors included the sequences flanking the proviral genome from the Stat 5 a sequence. MCS represents the location of the HindIII site (H) in the multiple-cloning site. $\mathbf{o}$, i, ii, iii, iv, $\mathbf{v}$, and $\mathbf{v i}$ in the schemes represent the ligated position of the provirus. The underlined letters indicate the palindromic motifs in the flanking sequences. The colored sequence is identical to the Stat $5 a$ sequence displayed in Figure 1A. The oligonucleotides CATT flanking the provirus were duplicated at the $5^{\prime}$ and $3^{\prime}$ ends of the provirus because such duplication in the integration site is commonly observed in Emv11 integration sites. Red CATTATC at the $3^{\prime}$ end of the provirus is the GATA family binding sequence. Italicized ATCACACTCCACTC at the $3^{\prime}$ side flanking sequence is the p300 binding sequence. In the iii, iv, and $\mathbf{v}$ vectors, the proviral genome was flanked by identical sequences at different sites. Arrows in $\mathbf{v}$ and $\mathbf{v i}$ indicate the reverse of the flanking sequence in $\mathbf{v}$ for making the vi construct. Vector vii was the negative control vector, including the Stat 5 a sequence alone. B: Luciferase activity (ratio of Firefly to Renilla luciferase signal) in Ba/F3 cells containing vectors. Individual assays were independently performed five times. Individual columns represent the data obtained using the five vectors indicated. $\mathbf{o}$ through $\mathbf{v}$ represent the integration sites of the provirus ( $n=5 ; 1$, o versus $\mathbf{i}, P=0.031 ; 2$, i versus ii, $P=0.024 ; 3$, ii versus $\mathbf{v}, P=0.011 ; 4$, ii versus iii, $P<0.001 ; 5$, ii versus iv, $P<0.001$; and 6 , v versus vi $P<0.001$ ). Table 1 contains additional information. Luciferase activity values were evaluated using the Student's $t$-test.

1134 segment, they were named Stat5ahigh clones. On the other hand, clones with integration into other sites were named Stat5alow clones.

Furthermore, to evaluate how STAT5A expression was promoted by the integrated $M L V$ genome, we attempted to analyze MLV-LTR-Stat5a chimera RNA. We found that the downstream Stat5a intron was serially transcribed after the RU5 element in the $5^{\prime}$-LTR of the provirus (Figure 1A). Therefore, the U3 segment of the $5^{\prime}$-LTR probably functioned as a promoter that up-regulated the expression of STAT5A.

\section{Upstream and Downstream Sequences of the Provirus Influenced Reporter Gene Expression}

The integration hot spots are within a 46-bp palindromic region containing transcription factor-binding sites. To examine whether the flanking sequence of the integration site might influence proviral promoter activity, luciferase assays were performed using seven pGL3-MLV-luciferase vectors consisting of a provirus or the downstream sequence, in- cluding CREB-, GATA-, and p300-binding motifs in Stat5a (Figure 2A). The Ba/F3 cells were selected for the assay because of their relative phenotypic similarity to the studied lymphoma cells, and luciferase reporter plasmids were transfected. Firefly luciferase activity was significantly upregulated when the vector consisting of intact Emv11-derived proviral genome was flanked by the Stat5a sequence. In particular, activity was stronger when the Emv11 proviral genome was flanked by a longer Stat5a sequence: $1, P=$ 0.031 , o versus i; $2, P=0$. 024, i versus ii; and $3, P=0.011$, ii versus v (Figure 2B). Of particular interest are vectors ii, iii, and iv, in which a proviral genome was integrated into different positions in the palindromic sequence, indicating that the symmetric location of the provirus in vector ii may be a critical factor for the higher activity of the promoter $(4, P<$ 0.001 , ii versus iii; and $5, P<0.001$, ii versus iv) (Table 1 and Figure $2 \mathrm{~B}$ ). In addition, the use of vector vi, which has the reverse flanking sequence of $\mathrm{v}$, resulted in significant down-regulation of luciferase $(6, P<0.001$, v versus vi) (Figure 2B), indicating that the flanking GATA- and p300binding motifs also influence promoter activity.

Table 1. Results of the Dual Luciferase Assay Using Modified Emv11 Genomes

\begin{tabular}{cccccc}
\hline Vector & Emv11 & Emv11-5'Runx1- & Emv11-3'Runx1- & Emv11-5'LTR & Emv11-3'LTR \\
\hline i & $0.008^{*}$ & $0.019^{*}$ & $0.021^{*}$ & $0.036^{*}$ & 0.214 \\
ii & $0.007^{*}$ & $0.028^{*}$ & $0.039^{*}$ & $0.018^{*}$ & 0.432 \\
iii & 0.071 & 0.267 & 0.398 & 0.291 & 0.291 \\
iv & 0.067 & 0.358 & 0.556 & 0.791 & 0.405 \\
v & $0.009^{*}$ & $0.032^{*}$ & $0.013^{*}$ & $0.012^{*}$ & 0.561 \\
\hline
\end{tabular}

Data are given as $P$ values for vector o versus five other vectors.

*Significant difference between vectors. 
A

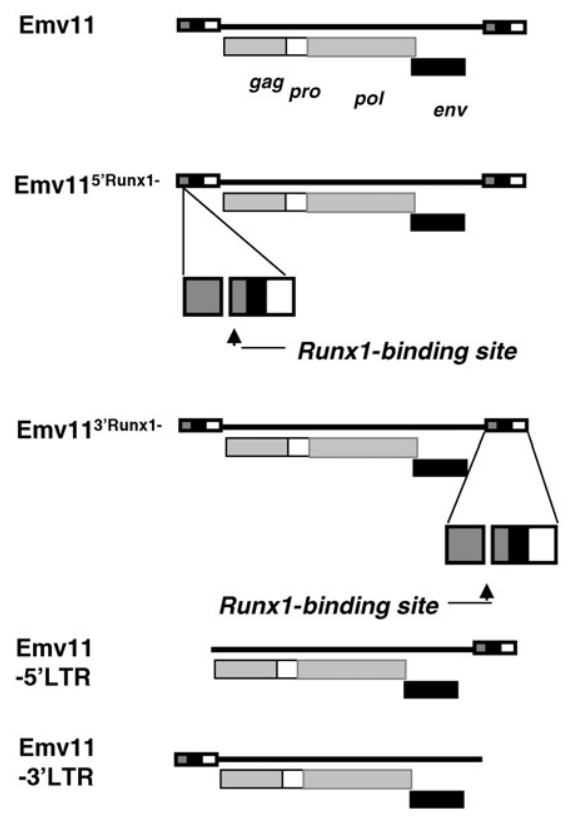

B
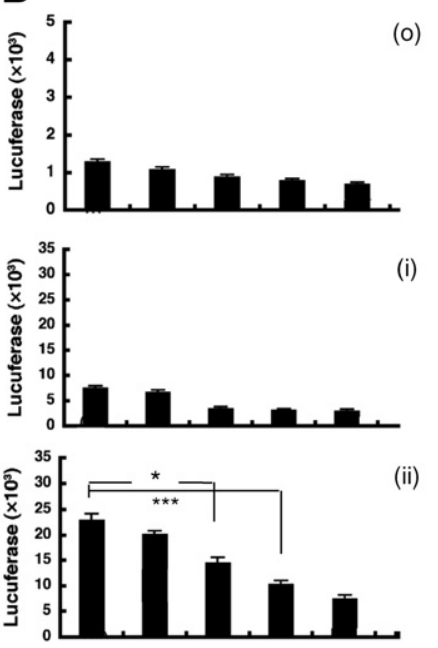

(ii)

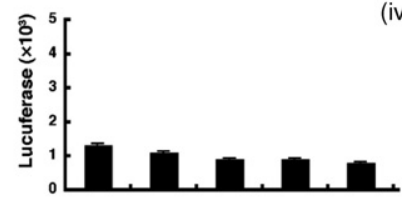

(iv)
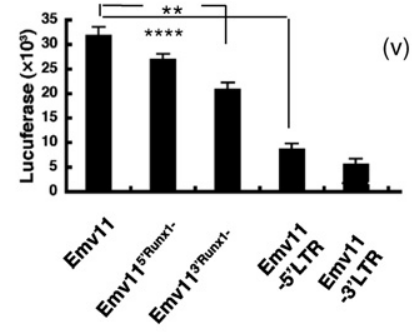

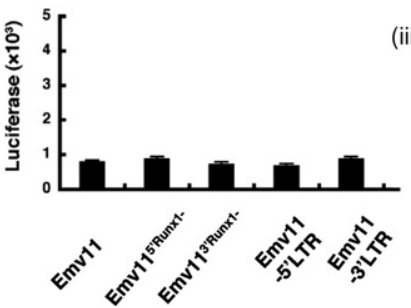

(iii)

3. Luciferase assay using modified Emv11 genomes. A: Structure of Emv11 constructs in the luciferase assay vectors. Native Emv11 is displayed at the top. Gag

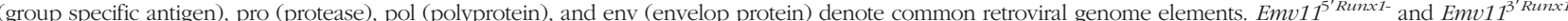
represent Emv11 lacking the Runx1-binding motif in 5'-LTR and 3'-LTR, respectively. Emv11-5'-LTR and Emv11-3'-LTR represent Emv11 lacking 5'-LTR and Emv11 lacking 3'-LTR, respectively. B: Luciferase assays. Luciferase activity (ratio of Firefly to Renilla luciferase signal) in Ba/F3 cells containing vectors. Individual assays were independently performed five times. Individual columns represent the data obtained using the five vectors indicated. $\mathbf{i}$ through $\mathbf{v}$ represent the vectors used. Table 2 contains additional information. For ii , ${ }^{*} P=0.032 ;{ }^{* * * *} P=0.028 ; \mathbf{v},{ }^{* *} P=0.041 ;{ }^{* * * * *} P=0.012$. Luciferase activity values were evaluated using the Student's $t$-test.

\section{Activity of the Proviral Promoter Element}

Next, we prepared five Firefly luciferase pGL3 vectors (o-v) at the HindlII site in the multicloning site into which defective proviral cDNA was inserted. These proviral DNAs in the vectors had defects in $3^{\prime}-L T R$ (Emv11-3'-LTR), 5'-LTR (Emv11-5'-LTR), the Runx1binding motif in $5^{\prime}$ LTR (Emv $v^{5^{\prime} R u n \times 1-}$ ), or the Runx1-binding motif in $3^{\prime}$-LTR (Emv ${ }^{3}$ Runx $1^{-}$) (Figure 3A). The vectors o through $v$ carrying individual proviral cDNA were transfected into $\mathrm{Ba} / \mathrm{F} 3$ pro-B cells.

The results showed that Firefly luciferase is significantly up-regulated even when the vector includes defective proviral genomes that are symmetrically flanked by palindromic motifs, as observed using intact Emv11 vectors (Figure 3B and Table $1 ; P<0.05$ for $\mathrm{i}$, ii, and $\mathbf{v}$ versus 0 ). There were significant increases in luciferase activity when using Emv11 inserted into ii and $v$ instead of $E m v^{3^{\prime} R u n \times 1-}$ inserted into ii and $\mathrm{v}$ [Figure 3B $\left({ }^{*} P=0.032\right.$ and $\left.{ }^{* *} P=0.041\right)$ and Table $2(n=5$, ii and v)]. In addition, there were significant increases when using Emv11 inserted into ii and v instead of Emv11-5'LTR (Figure 3B [ ${ }^{\star \star \star} P=0.028$ and ${ }^{\star \star \star *} P=0.012$ ] and Table $2[n=5$, ii and $\mathrm{v}]$ ). These data suggested that the Runx1-binding motif in 3'-LTR contributed to the up-regulation of downstream Firefly luciferase.

\section{GATA2-Binding Motif in the Flanking Sequence}

We analyzed the sequence motifs of the flanking sequences in host clone genomes. The GATA2-binding motif 5'-CAT-

Table 2. Results of the Dual Luciferase Assay

\begin{tabular}{ccccc}
\hline & \multicolumn{3}{c}{ Emv11 versus } \\
\cline { 2 - 5 } Vector & Emv11-5'Runx1- & Emv11-3'Runx1- & Emv11-5'LTR & Emv11-3'LTR \\
\hline i & 0.075 & 0.064 & 0.056 & $0.019^{*}$ \\
ii & 0.063 & $0.046^{*}$ & $0.028^{*}$ & $0.012^{*}$ \\
iii & 0.051 & 0.452 & 0.056 & 0.215 \\
iv & 0.085 & 0.673 & 0.081 & 0.366 \\
v & 0.062 & $0.037^{*}$ & $0.012^{*}$ & $0.006^{*}$ \\
\hline
\end{tabular}

Data are given as $P$ values for Emv11-carrying vectors versus individual defective Emv11-carrying vectors.

* Significant difference between vectors 


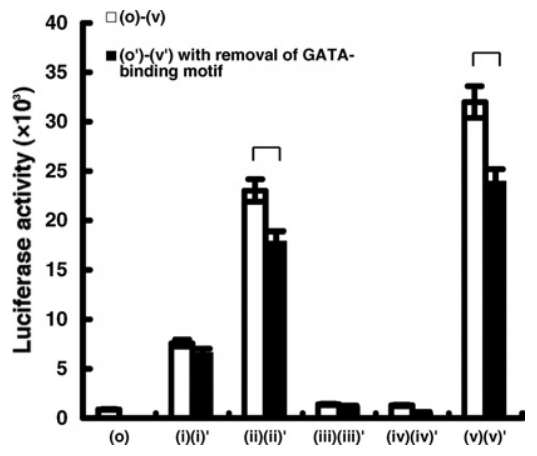

Figure 4. The GATA2-binding motif and retroviral promoter activity in luciferase assays. Relative luciferase activity is shown using vector constructs consisting of native or GATA2 motif defective flanking sequences. Individual assays were independently performed five times. The activity ratios (Firefly to Renilla luciferase) of $\mathbf{i i}$ and $\mathbf{v}$ were significantly higher than those of $\mathbf{i i}$ ' and $\mathbf{v}^{\prime}$, respectively (ii versus iii, ${ }^{*} P=0.031$; $\mathbf{v}$ versus $\mathbf{v}^{\prime}$, ${ }^{* *} P=0.028$ ). Measurements of luciferase activity were performed five times using individual vectors. Luciferase activity values were evaluated using the Student's $t$-test.

TATC-3' was observed in integration site 1130 of the Stat5a sequence that was included in vectors i, ii, iii, iv, and v (Figure 2A). To evaluate the contribution of the motif to luciferase activity, assays were performed using five modified vectors (i', ii', iii', iv', and v') from which the GATA2-binding motif in i, ii, iii, iv, and $\mathrm{v}$, respectively, had been removed. The results revealed that luciferase activity was significantly higher when vectors ii and $\mathrm{v}$ were used relative to when vectors ii ' and v', respectively, were used (Figure 4).

\section{IP of Transcriptional Factor Binding to the Provirus-Stat5a Junction}

We performed an IP assay using lymphoma clones and antibodies against proteins that have the potential to bind to LTR or the flanking sequences. The results revealed that Runx1 and integrase, GATA2 and integrase, GATA2 and p300, CREB-P1 and GATA2, and CREB-P1 and p300 form complexes (Figure 5A). Moreover, ChIP was performed using antibodies against Runx1, GATA2, and integrase. The precipitated DNA included Emv11 3'-LTRStat5a fusion genomic DNA in the Stat5ahigh clones (Figure 5B). Moreover, reperformed IP of DNA fragments that were precipitated by an antibody against GATA2 or GATA1 was done using an antibody against Runx1 and p300. The results revealed that the Emv11-3'-LTR-Stat5a segment was coimmunoprecipitated with GATA2-Runx1
A

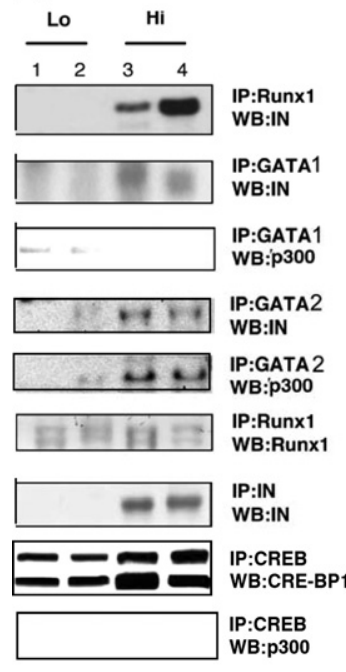

D

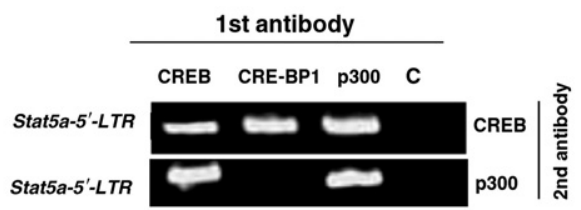

C Stat5ahigh (integration into +1134 )
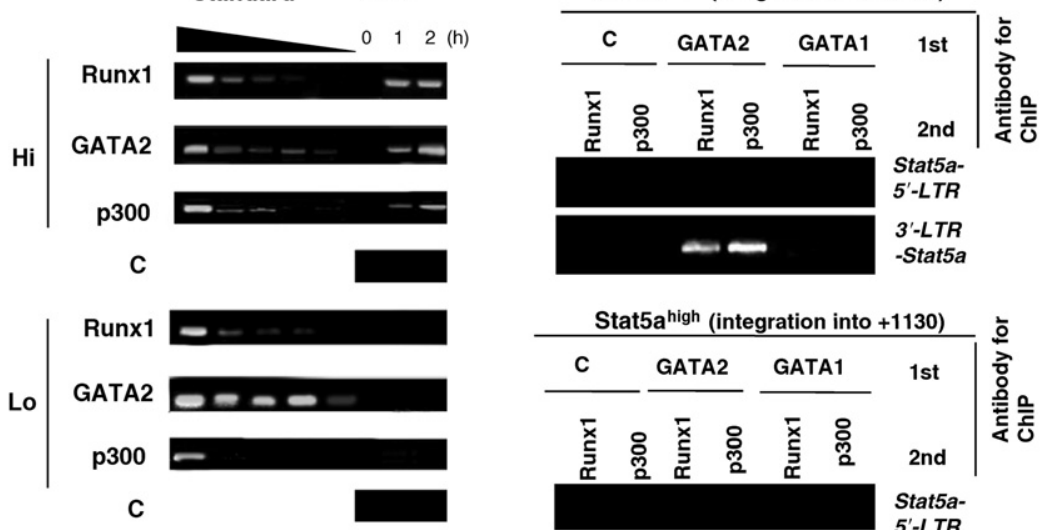

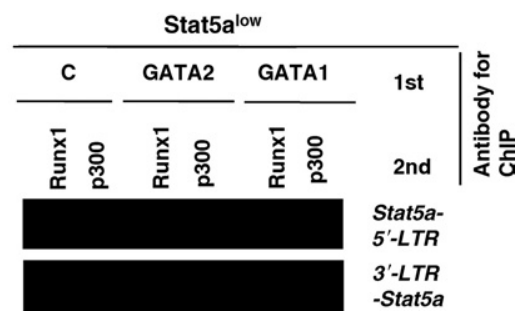

Figure 5. The IP of integrase (IN) complex and chromatin IP (ChIP) assays. Hi, Stat $5 \mathrm{a}^{\text {high }}$ clones; Lo, Stat $5 \mathrm{a}^{\text {low }}$ clones. A: The IP assay, lymphoma clone extracts WB indicates Western blot. Lanes 1 and 2: Stat5 $\mathrm{a}^{\text {low }}$ clones (integration sites, 1109 and 1115). Lanes 3 and 4: Stat5a ${ }^{\text {high }}$ clones (integration sites, 1126 and 1130 ). A photograph of WB using anti-CRE-BP1 revealed phosphorylated CRE-BP1 (upper band) and nonphosphorylated CRE-BP1. B: Reperformed ChIP-PCR assay. The chromatin preparation from $1.0 \times 10^{6}$ lymphoma cells was first immunoprecipitated with control and antibodies (first IP), and the immune complex was then eluted and reprecipitated with secondary antibodies (second IP). Primary and secondary antibodies used are shown. This also applies to the following figures. The upper photograph (Stat5a-5'-LTR) displays the results of PCR using primers between Stat5a and Emv11 5'-LTR. The lower photograph ( $3^{\prime}$-LTR- Stat5a) displays the results of PCR using primers between Emv11 3'-LTR and Stat5a. C: The ChIP-PCR assay. The photograph shows representative results of PCR using primers in the Emv113'-LTR and Stat $5 a$ third exon. The template DNA was extracted from chromatin preparations of $1.0 \times 10^{6}$ lymphoma cells and immunoprecipitated with antibodies against GATA2, Runx1, p300, or a normal rabbit IgG. Fivefold serial dilutions of total lymphoma DNA (standard) were amplified as an internal control of PCR using primers between -3346 and -2997 in the Stat $5 a$ gene ( $\mathrm{a}$ and b, Stat $5 \mathrm{a}^{\text {high }}$; and c, Stat5 $\mathrm{a}^{\text {low }}$ ). D: Reperformed ChIP-PCR assay. The labels were identical to those in C. 
A

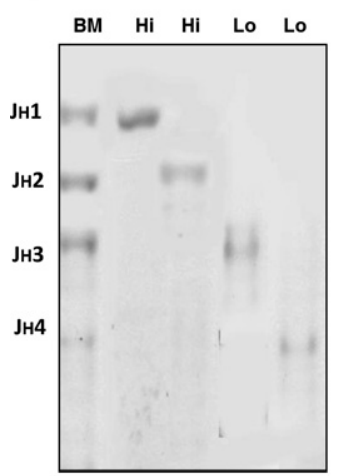

$\mathbf{V}_{\mathrm{H}} \mathrm{D}_{\mathrm{H}}$

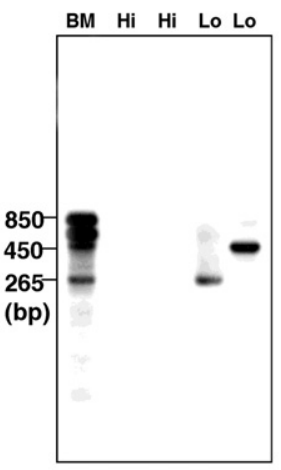

$\mathrm{V}_{\mathrm{k}} \mathrm{J}_{\mathrm{k}}$

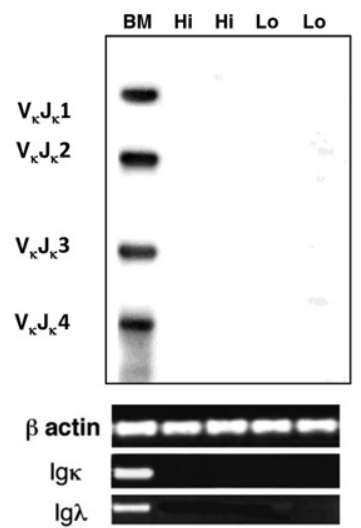

B

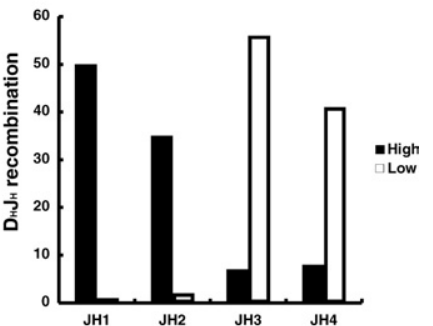

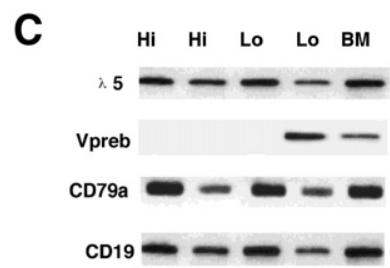

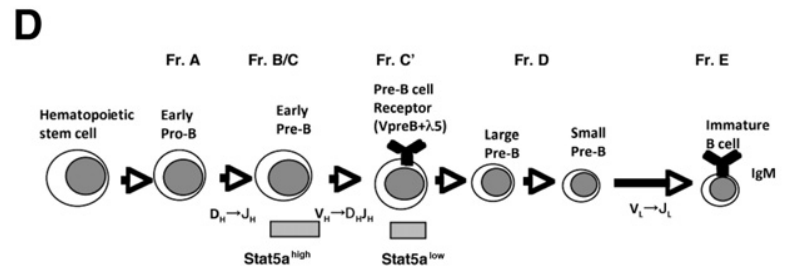

Figure 6. Development stages of pre-B lymphoma clones. A: Blots of $\mathrm{D}_{\mathrm{H}} \mathrm{J}_{\mathrm{H}}$, IgH variable segment $\left(\mathrm{V}_{\mathrm{H}}\right)$ and $\mathrm{D}_{\mathrm{H}}$, and $\mathrm{V} \kappa \mathrm{D} \kappa$ recombination. Hi indicates Stat $5 \mathrm{a}^{\text {high }}$ clones; Lo, Stat5 $\mathrm{a}^{\text {low }}$ clones; BM, pre-B cells of SL/Kh mice without the somatic Emv11 integration 3 weeks after birth. Lower: Results of the RT-PCR assay for Ig $\kappa$ and Ig $\lambda$ expression. B: Type of $\mathrm{D}_{\mathrm{H}} \mathrm{J}_{\mathrm{H}}$ recombination in the clones. Percentages of the dominant type in individual Stat $5 \mathrm{a}^{\text {high }}$ and Stat $5 \mathrm{a}^{\text {low }}$ clones are presented C: Results of RT-PCR for pre-B-cell receptor and other phenotypic markers. Hi indicates Stat $5 \mathrm{a}^{\text {high }}$ clones (with integration into 1130 ); Lo, Stat5a ${ }^{\text {low }}$ clones (with integration into 1138); $\mathrm{BM}$, pro-B cells obtained from SL/Kh mice 3 weeks after birth. D: Hardy's classification of Stat $5 \mathrm{a}^{\text {high }}$ clones and Stat5alow clones. Fr represents fraction. The stages of the $\mathrm{B}$-cell lineage are shown.

and GATA2-p300 complexes in Stat5a $\mathrm{a}^{\text {high }}$ clones (Figure 5C, a and b), whereas the Emv11-3'-LTR-Stat5a segment was not coimmunoprecipitated with these complexes (Figure 5C, c). In addition, the Emv11-3'-LTR-Stat5a segment from the clone with Emv11 integration into 1130 was coimmunoprecipitated with GATA1-Runx1 and GATA1p300 complexes (Figure 5C, b). Thus, the GATA-1 site could be referred to as a composite site that was formed de novo by the integration event. In addition, the Stat5aEmv11-5'-LTR fusion segment was coimmunoprecipitated with the CRE-BP1-CREB and p300-CREB complexes (Figure 5D).

\section{Integration Site Affects Maturation of Host Pro-B Lymphoma Cells}

We investigated the integration site to determine its influence on the phenotype of host lymphoma clones. The STAT5A is involved in the malignant transformation of pro- and pre-B phenotypes. ${ }^{17}$ The Stat5ahigh clones completed $\operatorname{lgH} \mathrm{D}_{\mathrm{H}_{\mathrm{H}}} \mathrm{J}_{\mathrm{H}}$ recombination but not IgH variable segment $-\mathrm{D}_{\mathrm{H}}$ recombination; on the other hand, Stat5alow clones completed both $\mathrm{D}_{\mathrm{H}} \mathrm{J}_{\mathrm{H}}$ and $\mathrm{ggH}$ variable segment- $D_{H}$ recombination. In both types of clones, Ig light chain recombination in $\lg \kappa$ and $\lg \lambda$ was not detected (Figure $6 A$ ). In the Stat5a $a^{\text {high }}$ clones, distal segments $J_{H} 1$ and $J_{H} 2$ were dominantly selected in $D_{H} J_{H}$ recombination, whereas in the Stat5alow clones, proximal segments $J_{H} 3$ and $J_{H} 4$ were dominantly selected (significant findings) (Figure 6B). In addition, RT-PCR assays revealed that Stat5 $a^{\text {high }}$ clones were high for $\lambda 5$ but low for Vpreb, surrogate light chain components of pre-B-cell receptor; in contrast, Stat5a ${ }^{\text {low }}$ clones were constitutively high for both $\lambda 5$ and Vpreb. However, Vpreb expression was not constitutively high in Stat5alow clones (Figure 6C). In summary, according to the murine B-cell classification of Hardy et $\mathrm{al}^{18}{ }^{18}$ the Stat5a ${ }^{\text {high }}$ clones belonged to fraction $\mathrm{B} / \mathrm{C}$ (pro- to early pre-B cells) and were more immature than other Stat5a ${ }^{\text {low }}$ clones that belonged to fraction C' (pre-B cells) (Figure 6D). Thus, different integration sites of MLV influenced the development stage of the host cells.

\section{Stimulation by IL-7 Receptor Suppressed Ig Light Chain Recombination in the Stat5a ${ }^{\text {high }}$ Lymphoma Clones}

We then analyzed the effect of IL-7, one of the activation factors of signaling pathways that recruit STAT5A, on the development of Stat5ahigh clones. The clones were first incubated for 24 hours in a medium without IL-7 to suppress intrinsic stimulation by IL-7 responses. Then, the knockdown of Stat5a was achieved by transfection of RNAi into the clones, performed with or without IL-7 for 120 hours. The knockdown was confirmed by Western blot analysis using an antibody toward STAT5A (Figure 7A).

After transfection, the expression of $\lg \kappa$ and $\lg \lambda$ was investigated by measuring the intensity of the Western blot. After incubation for 120 hours without Stat5a knockdown, IL-7 in the culture medium effectively suppressed $\lg \kappa$ and $\lg \lambda$ expression in Stat5ahigh lymphoma clones (i versus ii); in contrast, the suppression was not evident in 


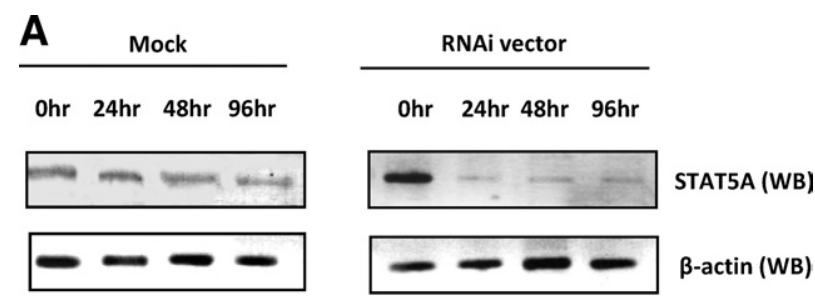

B
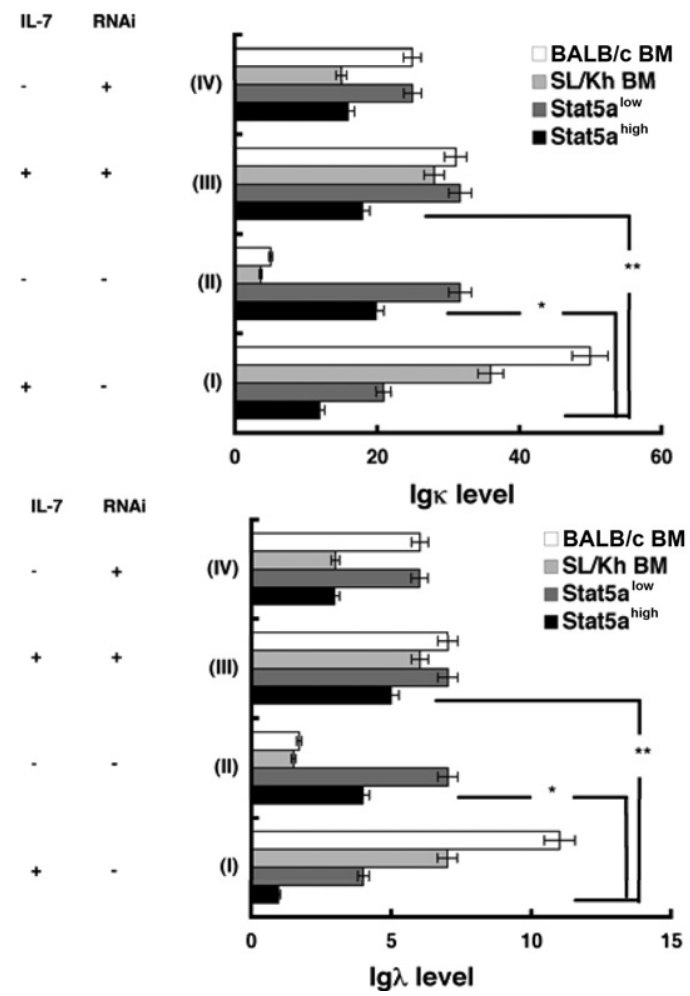

Figure 7. Arrest of Ig light chain (IgL) recombination in the Stat $5 \mathrm{a}^{\text {high }}$ lymphoma clones supplemented with IL-7. A: Western blots (WBs) of the Stat $5 \mathrm{a}^{\text {high }}$ clone with knockdown using control or both Stat $5 a$ - and Stat $5 b$ RNAi with $50 \mathrm{ng} / \mathrm{ml} \mathrm{IL-7}$ or without IL-7 added. $\beta$-Actin was used as the control. B: The relative fluorescence intensity of $\operatorname{Ig} \kappa$ and $\operatorname{Ig} \lambda$. For Stat $5 \mathrm{a}^{\text {high }}$, integration sites were $1124,1126,1130$ (three clones), and 1134; Stat5a $\mathrm{a}^{\text {low }}$, integration sites were 1100, 1102, 1109, 1113, 1115, and 1138; SL/Kh BM, sorted normal pro-B cells without Emv11 integration into Stat5a in the BM of SL/Kh mice; BALB/C BM, sorted control pro-B cells in the BM of BALB/c mice; + and - , presence and absence of $50 \mathrm{ng} / \mathrm{ml} \mathrm{IL-7}$ in the incubation medium for 96 hours, respectively. Top: $\mathbf{i}$ versus $\mathbf{i i},{ }^{*} P=0.034(n=5)$; and $\mathbf{i}$ versus iii, ${ }^{* * k} P=$ $0.041(n=5)$. Bottom: $\mathbf{i}$ versus $\mathbf{i i},{ }^{*} P=0.013$; and $\mathbf{i}$ versus iii, ${ }^{* *} P=0.023$. Assays were independently performed five times using four Stat $5 \mathrm{a}^{\text {high }}$ clones and four Stat $5 \mathrm{a}^{\text {low }}$ clones. Luciferase activity was assessed using Student's $t$-test.

Stat5a ${ }^{\text {low }}$ lymphoma clones (Figure 7). Incubation for 120 hours of the knockdown of Stat5a with IL-7 resulted in Ig $\kappa$ and $\lg \lambda$ expression in Stat5ahigh lymphoma clones (i versus iii). Thus, the suppressive effect of IL-7 on Ig $\kappa$ and Ig $\lambda$ expression was exclusively evident in Stat5ahigh lymphoma clones, indicating that the suppressive effect was dependent on the expression level of Stat5a.

\section{IL-7 Receptor Stimulation Suppressed Apoptosis in the Stat5a high Lymphoma Clones}

There was an antiapoptotic effect of high expression of Stat5a. The clones were first incubated for 24 hours in a medium without IL-7 to suppress intrinsic stimulation by

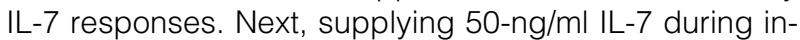
cubation resulted in significant up-regulation of the expression of $\mathrm{Bcl}-\mathrm{xL}$, an antiapoptotic protein, in the Stat5a ${ }^{\text {high }}$ clones (Figure 8A). As previously reported, the $b c l-x L$ gene carries a gamma interferon activation site element in the promoter for enhancing dimeric STAT5A binding. ${ }^{19}$ When $\mathrm{IL}-7$ was supplemented, the relative densities of $\mathrm{Bcl}-\mathrm{xL}$ and phosphorylated STAT5A closely correlated with each other $(P<0.001, n=5)$ (Figure 8B).

Next, we performed an electromobility shift assay to investigate whether STAT5A protein can bind to the $b c / x L$ gene promoter after various levels of IL-7 stimulation using oligonucleotides corresponding to the STAT5A-binding motif on the murine $b c l-x L$ gene promoter as a probe. After the addition of an antibody to the nuclear extracts, supershifts of the DNA binding complex were observed in an IL-7 dose-dependent manner (Figure 8C).

To confirm the effect of the increase in $b c / x L$ gene expression, the ratio of annexin $\mathrm{V}$-positive apoptotic cells in the lymphoma clones was determined, with or without the addition of a cytokine supplement during the incubation. The results revealed that apoptotic cells were significantly less prevalent in Stat5ahigh clones incubated with IL-7 (Figure 8D).

\section{Discussion}

The obtained data were used to construct a model to demonstrate why integration of a proviral genome into the specified location in the host sequence causes higher promoter activity and maturation arrest of the host cell (Figure 9). First, we found that Runx1, GATA2, and p300 bound to the $3^{\prime}$-LTR-Stat5a in the Stat5a ${ }^{\text {high }}$ clones (Figure $5, \mathrm{~B}$ and $\mathrm{C}$ ). Next, we confirmed that CREB, CREBP1, and p300 bound to the 5'-LTR-Stat5a in the Stat5a ${ }^{\text {high }}$ clones (Figure 5D). This CREB protein has the potential to associate with CRE-BP1 and p300 in B cells and to control the transcription of the target gene. Therefore, CREB can be a scaffold for the recruitment of p300 on the LTR-Stat5a sequence DNA. Novel control of the CREB-dependent transcription of the target gene by a member of the regulator of G-protein signaling protein family in B cells has been reported. ${ }^{20,21}$ The p300 increases target gene expression in several ways (ie, relaxing the chromatin structure at the gene promoter through its intrinsic histone-acetyltransferase activity and recruiting the general transcriptional machinery, including RNA polymerase II, to the promoter). In B cells, B-cell receptor linking induces histone lysine acetylation at the Bruton's tyrosine kinase promoter, correlating with marked recruitment of p300 to the locus. ${ }^{22}$ Another recent study ${ }^{23}$ reported that a paired box protein Pax5mediated B-cell development was controlled by p300. Pax5 is a B-cell-specific activator protein that plays important roles in controlling the expression of lineage and differentiation stage-specific genes during B lymphopoiesis. Furthermore, p300 is a coactivator for transcription factor REL and is $C$ terminally truncated in the human diffuse large B-cell lymphoma cell line. ${ }^{24}$ Thus, p300 contributes to B- 
A
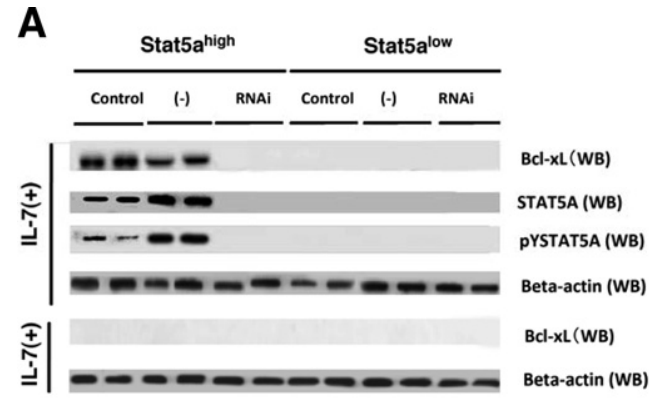

C

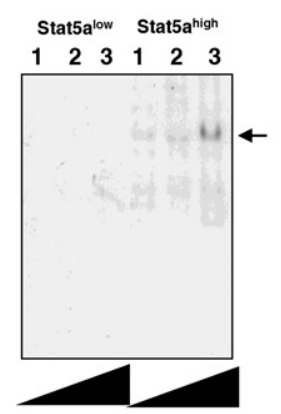

D
B
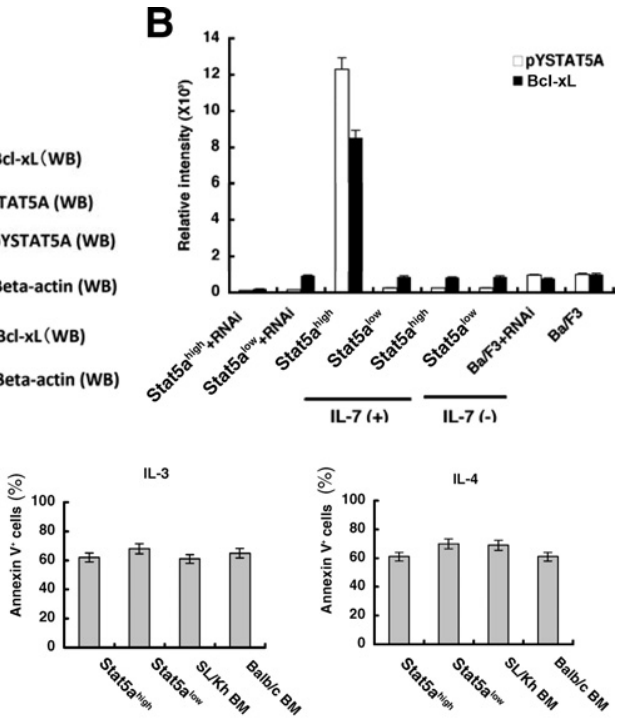

IL-7

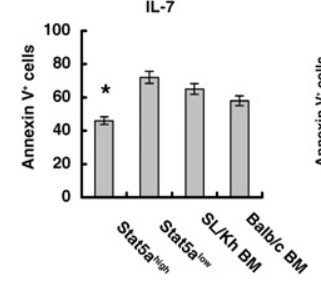

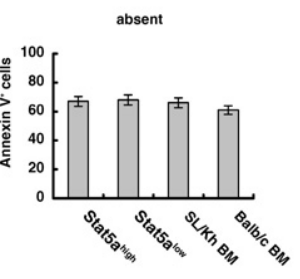

Figure 8. Expression of $\mathrm{Bcl}-\mathrm{xL}$ in lymphoma clones. A: The RT-PCR assay of $b c l-x L$ using Stat $5 \mathrm{a}^{\text {high }}$ and Stat $5 \mathrm{a}^{\text {low }}$ lymphoma clones. WB indicates Western blot. B: Relative density of the WBs for phosphorylated STAT5A (pYSTAT5A) and Bcl-xL. The density was measured with chemiluminator LumiVision. C: Identification of Stat5A binding by supershift analysis. Lanes 1, 2, and 3: Nuclear extracts of lymphoma cells stimulated with 0,20 , and $40 \mathrm{ng} / \mathrm{mL}$ of recombinant murine IL-7, respectively. The arrow highlights the supershift. D: Percentage of annexin $\mathrm{V}$-positive cells in the population of lymphoma cells incubated with or without cytokines ( $n=5,{ }^{*} P<0.05$, Stat $5 \mathrm{a}^{\text {high }}$ versus others) cell development and lymphomagenesis. The histoneacetyltransferase activity of p300 modulates human Tlymphotropic virus-I LTR transcriptional activity. ${ }^{25}$ Herein, we hypothesize that $\mathrm{p} 300$ bindings may promote the expression of MLV and the target Stat5a. Although there have been few reports regarding the relation of p300 with
MLV LTR transcriptional activity, we suppose that direct p300 binding to the upstream sequence of the provirus or an indirect effect via association with CREB binding to the upstream sequence up-regulates the transcriptional activity; in addition, p300 binding to the downstream sequence may contribute to the transcriptional activity

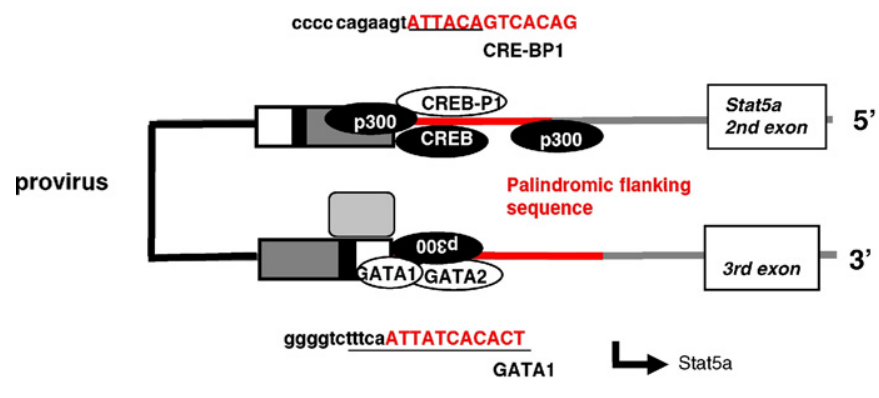

Nucleus

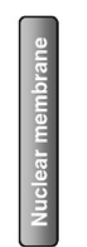

5'

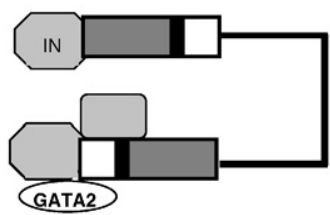

Pre-integration complex

Figure 9. Model of the complex promoting transcription of the target gene. Transcription factor complexes on the LTR-Stat5a sequence. The provirus is integrated into 1130 and into another site. Transcription of LTR started from the RU5 element on the proviral genome. Lines by the sequence represent the CRE-BP1 and GATA1 motifs. The sequences next to the viral Stat5a segment display the motifs of p300, CREB, CRE-BP1, GATA2, Runx1, and GATA1. Lowercased letters represent MLV-LTR element sequences; and uppercased letters, Stat5a sequences. IN indicates integrase. 
Table 3. MLV Integrations Near the Coding Region

\begin{tabular}{lccc}
\hline \multirow{2}{*}{$\begin{array}{c}\text { Host gene located downstream of the integration } \\
\text { site }\end{array}$} & \multicolumn{3}{c}{ Mouse chromosome } \\
\cline { 2 - 4 } Location \\
\hline ATPase, $\mathrm{H}^{+}$-transporting, V1 subunit G isoform 2 & 3,623 and 3,723 & No. & NT_039649 \\
FC- $\gamma$ receptor & 155,834 & 3 & NT_39240 \\
GRP1-binding protein GRSP1 (Frmd4b) & 16,330 & 6 & NT_039353.7 \\
Myosin, heavy polypeptide 9, nonmuscle isoform 1 & 22,229 & NT_039621.7 \\
Similar to Gpd1l protein & 5,189 & 5 & NW_001030784.1 \\
Similar to high-mobility group box 1 & 22,452 & 15 & NT_039621.7 \\
3-Hydroxyanthranilate-3,4-dioxygenase & 292,004 & 17 & NW_001030622.1 \\
Testicular serine protease 1 & 7,060 & 1 & NT_039170.7 \\
\hline
\end{tabular}

downstream of Stat5a (Figure 2A, ii). This multiplier effect of p300 downstream and upstream of the provirus may contribute to a significant increase in the proviral promoter activity and the higher expression of Stat5a. A plausible regulation is that the palindromic sequence contributed to the stabilization of the relaxed chromatin by generation of a secondary structure, such as a cruciform or hairpin structure in the single-stranded DNA. Significantly, acetylation of HIV-1 integrase by p300 regulates viral integration. ${ }^{26,27}$ Studamire and Goff ${ }^{28}$ reported host proteins interacting with the Moloney murine leukemia virus integrase. In the future, other interacting proteins will be identified, and p300 may be among them.

When MLV is integrated into the most frequent integration site (ie, 1130), the de novo GATA1-binding motif appears in the provirus-host junctional sequence (Figure 5C). Indeed, the IP assay shown in Figure 5C indicates that GATA1 binds to the Emv11 3'-LTR-Stat5a segment. Thus, the proviral terminal sequence DNA connected to the host sequence DNA carries several potential transcription factor-binding motifs. The binding GATA1 may be controlled by acetylation by CRE-BP1.29

In the current study, a significant amount of integrase was unexpectedly observed in the lymphoma clones. The mean \pm SD of $68 \pm 17$ nonclonal integration sites was identified in an examined clone by an inverse PCR method; the integration sites that are relatively close to the coding regions are listed in Table 3 . These data suggested that MLV integration constitutively occurred in the lymphoma cells. In actuality, expression of ecotropic virus Emv11 by neonatal injection of maternal resistance factor inhibits lymphomagenesis. ${ }^{11}$ It is probable that MLV particles were provided by individual lymphoma cells and that the MLV reinfected neighboring lymphoma cells during tumor development, with translocation of integrase into the nucleus. This SL/Kh strain of mice possesses more than six copies of endogenous retroviruses in the germ line (Figure 1B). Six is a far higher number than that in other strains of mice, such as AKR. ${ }^{12} \mathrm{~A}$ previous report ${ }^{11}$ shows that two of these endogenous retroviruses have the potential to be transcribed into producing complete viral particles. In this study, we found three endogenous retroviruses other than Emv11 (see Supplemental Table S1 at http://ajp.amjpathol.org). These endogenous retroviral transcriptional mechanisms and functions are not entirely understood, and further study will be required for consideration of a model in which integrase interacts with transcriptional factors in the host cells. Notably, Kitamura et al reported that human endogenous retrovirus $\mathrm{K} 10$ encodes a functional integrase. ${ }^{30}$

Our data clearly show that the Emv11 integration site influences host phenotype via the maturation arrest of the $\mathrm{IgH}$ recombination. These influences by the integration site remain poorly understood, and insufficient attention has been paid to host phenotypic changes aside from Emv11 tumorigenesis. However, as shown in the current study, the integration site can have variable effects on host phenotype via integration. Although our study is limited to $\mathrm{lgH}$ recombination in the presence of $\mathrm{IL}-7$, the cell culture conditions may affect the host cell phenotype by the integration. In this model, we added evidence that STAT5A may contribute to the tumorigenesis of pre-B lymphoma/leukemia. In actuality, there have been reports $^{31,32}$ that mutations of Janus kinase 2, which phosphorylates STAT5, in acute lymphocytic leukemia are associated with Down's syndrome. Thus, the contribution of STAT5 to leukemogenesis has been commonly accepted. Our study model could be one of the models of lymphoblastic tumorigenesis.

The MLV vectors are essential tools for the generation of induced pluripotent stem cells. Nevertheless, the data presented herein provide significant information about the phenotypes of transgenic animals carrying the MLV vector. A minute difference between MLV integration sites can lead to large differences in host phenotype, suggesting that caution should be advised in monitoring integration sites when working with MLV vectors.

\section{Acknowledgments}

We thank Dr. Hiroshi Hiai (Kyoto University, Kyoto, Japan) for overview and critical advice regarding the manuscript; Dr Tasuku Honjo, Kyoto University, for critical advice regarding the manuscript; and Ms. H. Saito for providing technical assistance.

\section{References}

1. Hacein-Bey-Abina S, Von Kalle C, Schmidt M, McCormack MP, Wulffraat $N$, Leboulch $P$, Lim A, Osborne CS, Pawliuk R, Morillon E, Sorensen R, Forster A, Fraser P, Cohen JI, de Saint Basile G, Alexander I, Wintergerst U, Frebourg T, Aurias A, Stoppa-Lyonnet D, Romana S, Radford-Weiss I, Gross F, Valensi F, Delabesse E, Macintyre E, Sigaux F, Soulier J, Leiva LE, Wissler M, Prinz C, Rabbitts TH, LE Deist F, Fischer A, Cavazzana-Calvo M: LMO2-associated clonal 
T cell proliferation in two patients after gene therapy for SCID-X1. Science 2003, 302:415-419

2. Nakagawa M, Koyanagi M, Tanabe K, Takahashi K, Ichisaka T, Aoi T, Okita K, Mochiduki Y, Takizawa N, Yamanaka S: Generation of induced pluripotent stem cells without Myc from mouse and human fibroblasts. Nature Biotechnol 2008, 26:101-106

3. Akagi K, Suzuki T, Stephens RM, Jenkins NA, Copeland NG: RTCGD: retroviral tagged cancer gene database. Nucleic Acids Res 2004, 32:D523-D527

4. Tsuruyama $T$, Nakamura $T$, Jin G, Ozeki M, Yamada $Y$, Hiai $H$ Constitutive activation of Stat5a by retrovirus integration in early pre-B lymphomas of SL/Kh strain mice. Proc Natl Acad Sci U S A 2002, 99:8253-8258

5. Matsumura I, Kitamura T, Wakao H, Tanaka H, Hashimoto K, Albanese C, Downward J, Pestell RG, Kanakura Y: Transcriptional regulation of the cyclin D1 promoter by STAT5: its involvement in cytokinedependent growth of hematopoietic cells. EMBO J 1999, 18:13671377

6. Nosaka T, Kawashima T, Misawa K, Ikuta K, Mui AL, Kitamura T: STAT5 as a molecular regulator of proliferation differentiation and apoptosis in hematopoietic cells. EMBO J 1999, 17:4754-4765

7. Kirito K, Watanabe T, Sawada K, Endo H, Ozawa K, Komatsu N: Thrombopoietin regulates $\mathrm{Bcl}-\mathrm{xL}$ gene expression through Stat5 and phosphatidylinositol 3-kinase activation pathways. J Biol Chem 2002, 277:8329-8337

8. Chowdhury D, Sen R: Stepwise activation of the immunoglobulin mu heavy chain gene locus. EMBO J 2000, 20:6394-6403

9. Sexl V, Piekorz R, Moriggl R, Rohrer J, Brown MP, Bunting KD Rothammer K, Roussel MF, Ihle JN: Stat5a/b contribute to interleukin 7-induced B-cell precursor expansion but abl- and bcr/abl-induced transformation are independent of Stat5. Blood 2000, 96:2277-2283

10. Schwaller J, Parganas E, Wang D, Cain D, Aster JC, Williams IR, Lee CK, Gerthner R, Kitamura T, Frantsve J, Anastasiadou E, Loh ML, Levy DE, Ihle JN, Gilliland DG: Stat5 is essential for the myelo- and lymphoproliferative disease induced by TEL/JAK2. Mol Cell 2000, 6:693-704

11. Abujiang $P$, Yamada $Y$, Haller $O$, Kobayashi H, Kamoto $T$, Lu LM, Ogawa M, Ishimoto A, Katoh H, Kanehira K, Ikegami S, Fukumoto M, Hiai H: The origin of SL family mice. Lab Anim Sci 1996, 62:410-417

12. Mucenski ML, Bedigian HG, Shull MM, Copeland NG, Jenkins NA: Comparative molecular genetic analysis of lymphomas from six inbred mouse strains. J Virol 1988, 62:839-884

13. Pennycook JLMH, Marshall AJ, Wu GE: PCR assays for endogenous Ig gene rearrangement. Immunology Methods Manual, vol 1. Edited by I Lefkovits. San Diego, Academic Press, 1997, pp 564

14. Ye SK, Maki K, Kitamura T, Sunaga S, Akashi K, Domen J, Weissman IL, Honjo T, Ikuta K: Induction of germline transcription in the TCR $\gamma$ locus by Stat5: implications for accessibility control by the IL-7 receptor. Immunity 1999, 11:213-223

15. Ishihara K, Satoh I, Nittoh T, Kanaya T, Okazaki H, Suzuki T, Koyama T, Sakamoto T, Ide T, Ohuchi K: Preparation of recombinant rat interleukin- 5 by baculovirus expression system and analysis of its biological activities. Biochim Biophys Acta 1999, 1451:48-58

16. Shang Y, Hu X, DiRenzo J, Lazar MA, Brown M: Cofactor dynamics and sufficiency in estrogen receptor-regulated transcription. Cell 2000, 103:843-852
17. Santos SC, Lacronique V, Bouchaert I, Monni R, Bernard O, Gisselbrecht S, Gouilleux F: Constitutively active STAT5 variants induce growth and survival of hematopoietic cells through a PI 3-kinase/Akt dependent pathway. Oncogene 2001, 20:2080-2090

18. Hardy RR, Carmack CE, Shinton SA, Kemp JD, Hayakawa K: Resolution and characterization of pro-B and pre-pro-B cell stages in normal mouse bone marrow. J Exp Med 1991, 173:1213-1225

19. Socolovsky M, Fallon A, Wang S, Brugnara C, Lodish H: Fetal anemia and apoptosis of red cell progenitors in Stat5a-/-5b-/- mice: a direct role for Stat5 in Bcl-XL induction. Cell 1999, 98:181-191

20. Vo N, Goodman RH: CREB-binding protein and p300 in transcriptional regulation. J Biol Chem 2001, 276:13505-13508

21. Xie Z, Geiger TR, Johnson EN, Nyborg JK, Druey KM: RGS13 acts as a nuclear repressor of CREB. Mol Cell 2008, 31:660-670

22. Spiegelman BM, Heinrich R: Biological control through regulated transcriptional coactivators. Cell 2004, 119:157-167

23. Lee IS, Choi WH, Kim JY, Jeong JY, Kim MJ, Nam JH, Kim JH, Seo $\mathrm{SB}$, Pak JH: Transcriptional regulation of the murine 1-cys peroxiredoxin gene by the B cell-specific activator protein, Pax5. J Cell Biochem 2008, 104:465-476

24. Garbati MR, Alço G, Gilmore TD: Histone acetyltransferase p300 is a coactivator for transcription factor REL and is C-terminally truncated in the human diffuse large B-cell lymphoma cell line RC-K8. Cancer Lett 2010, 291:237-245

25. Michael B, Nair AM, Datta A, Hiraragi H, Ratner L, Lairmore MD: Histone acetyltransferase (HAT) activity of p300 modulates human T lymphotropic virus type 1 p30ll-mediated repression of LTR transcriptional activity. Virology 2006, 354:225-239

26. Cereseto A, Manganaro L, Gutierrez MI, Terreni M, Fittipaldi A, Lusic M, Marcello A, Giacca M: Acetylation of HIV-1 integrase by p300 regulates viral integration. EMBO J 2005, 24:3070-3081

27. Raghavendra NK, Shkriabai N, Graham RLJ, Hess S, Kvaratskhelia M, Wu L: Identification of host proteins associated with HIV-1 preintegration complexes isolated from infected CD4+ cells. Retrovirology 2010, 7:66

28. Studamire B, Goff SP: Host proteins interacting with the Moloney murine leukemia virus integrase: multiple transcriptional regulators and chromatin binding factors. Retrovirology 2008, 5:48

29. Hung HL, Lau J, Kim AY, Weiss MJ, Blobel GA: CREB binding protein acetylates hematopoietic transcription factor GATA-1 at functionally important sites. Mol Cell Biol 1999, 19:3496-3505

30. Kitamura Y, Ayakawa T, Ishikawa T, Kanda T, Yoshiike K: Human endogenous retrovirus $\mathrm{K} 10$ encodes a functional integrase. J Viro 1996, 70:3302-3306

31. Bercovich D, Ganmore I, Scott LM, Wainreb G, Birger Y, Elimelech A, Shochat C, Cazzaniga G, Biondi A, Basso G, Cario G, Schrappe M, Stanulla M, Strehl S, Haas OA, Mann G, Binder V, Borkhardt A, Kempski H, Trka J, Bielorei B, Avigad S, Stark B, Smith O, Dastugue N, Bourquin JP, Tal NB, Green AR, Izraeli S: Mutations of JAK2 in acute lymphoblastic leukaemias associated with Down's syndrome. Lancet 2008, 372:1484-1492

32. Kearney L, Gonzalez De Castro D, Yeung J, Procter J, Horsley SW, Eguchi-Ishimae M, Bateman CM, Anderson K, Chaplin T, Young BD, Harrison CJ, Kempski H, So CW, Ford AM, Greaves M: Specific JAK2 mutation (JAK2R683) and multiple gene deletions in Down syndrome acute lymphoblastic leukemia. Blood 2009, 113:646-648 